\title{
"Não quebrou a corrente, mas abriu um elo entre nós": o impacto da dependência química materna sobre o vínculo mãe-filho
}

\author{
Vanessa Trindade ${ }^{1}$ \\ Carolina Bunn Bartilotti ${ }^{2}$
}

\begin{abstract}
Esta pesquisa objetivou identificar a percepção de cinco mães dependentes químicas da Grande Florianópolis acerca do vínculo com seus filhos, antes e durante a recuperação. Os dados foram coletados em entrevistas semiestruturadas e analisados pela técnica de Análise de Conteúdo. Constatou-se que no período de uso de drogas a prioridade esteve voltada a este consumo, gerando afastamento entre mães e filhos. Concluiu-se que o uso de drogas pelas mães traz consequências significativas à relação mãe-filho, gera afastamento, fragiliza vínculos e prejudica o exercício do papel materno. Assim, as intervenções dos profissionais da saúde com estas mulheres devem abordar aspectos para além do comportamento de usar drogas, abrangendo questões referentes ao papel como mãe e mulher, inseridas em uma realidade social.
\end{abstract}

Descritores: Transtornos Relacionados ao Uso de Substâncias; Maternidade; Relações Mãe-Filho.

\footnotetext{
${ }^{1}$ Psicóloga.

${ }^{2} \mathrm{PhD}$, Professor, Universidade do Sul de Santa Catarina, Palhoça, SC, Brasil.
} 


\title{
"The chain has not broken, but opened a link between us": the impact of maternal chemical dependency on the mother-child bond
}

\begin{abstract}
This research aimed to identify the perception of five drug addict mothers of Florianópolis about the bond with their children before and during recovery. Data were collected in semistructured interviews and analyzed by Content Analysis technique. During the drug use period, the priority was focused on drug consumption, creating a gap between mothers and children. We concluded that mothers' drug use causes significant consequences to the mother-child relationship, generates distance, weakens bonds and affects the exercise of maternal role. Thus, interventions of health professionals with these women should address aspects beyond the behavior of using drugs, including issues related to the role as mother and woman, in a social reality.
\end{abstract}

Descriptors: Substance-Related Disorders; Maternity; Mother-Child Relations.

\section{"No quebró la corriente, pero abrió un eslabón entre nosotros": el impacto de la dependencia química materna sobre el vínculo madre-hijo}

\begin{abstract}
Esta pesquisa objetivó identificar la percepción de cinco madres dependientes químicas de la Grande Florianópolis acerca del vínculo con sus hijos, antes y durante la recuperación. Los datos fueron colectados en entrevistas semiestruturadas y analizados por la técnica de Análisis de Contenido. Se constató que en el período de uso de drogas la prioridad estuvo vuelta a este consumo, generando alejamiento entre madres e hijos. Se concluyó que el uso de drogas por las madres trae consecuencias significativas a la relación madre-hijo, genera alejamiento, debilita vínculos y perjudica el ejercicio del papel materno. Así, las intervenciones de los profesionales de la salud con estas mujeres deben abordar aspectos más allá del comportamiento de usar drogas, abarcando cuestiones referentes al papel como madre y mujer, inseridas en una realidad social.
\end{abstract}

Descriptores: Trastornos Relacionados con Sustancias; Maternidad; Relaciones Madre-Hijo.

\section{Introdução}

A sociedade atual atribui à mãe um papel fundamental no contexto familiar e, em especial, na formação dos filhos; de modo que a principal função materna é ser "nutridora"(1). Este papel é representado pelo suporte às necessidades do filho, tal como higiene, alimentação, vínculo afetivo, dentre outro $\mathrm{s}$. As experiências que a criança tem em sua relação com a mãe, tanto positivas quanto negativas, inscreverão em sua subjetividade formas e tendências de lidar com a sociedade e perceber o mundo a sua volta(1).

$\mathrm{O}$ vínculo afetivo estabelecido entre mãe e filho é um processo compreendido como gradual, pois cresce e se solidifica depois de repetidas experiências positivas e prazerosas. Neste processo ocorre uma espécie de retroalimentação emocional, pois, à medida que há um investimento emocional da mãe 
para o filho, há o desenvolvimento do elo de apego que a criança nutre com relação à mãe $e^{(2)}$. Assim, o crescimento do investimento emocional tende a estar amplamente vinculado ao crescimento do apego sendo a qualidade desta relação determinante para a formação da consciência que a criança tem de si e da forma que esta se colocará no mundo e nas relações.

Dada a importância do papel materno, a sociedade contemporânea exige que a mãe tenha um amor incondicional para com seus filhos e que a eles seja dada atenção e cuidados, tanto quanto possível. Assim, espera-se que o filho seja sua maior prioridade, maior fonte de amor e carinho. Inclusive, há algumas décadas, era comum que os únicos papéis atribuídos à mulher fossem o de mãe e dona de casa(3).

Progressivamente, com os espaços e direitos conquistados pelas mulheres, como sua participação na esfera pública, entrada no mercado de trabalho e consequente independência financeira, a realidade da mulher-mãe vem se alterando(3). A mulher de hoje tem, não raro, adiado a maternidade em função de conquistas profissionais e acadêmicas. Entretanto, ainda é comum as pessoas reagirem com estranheza ao ouvirem que uma mulher não deseja ser mãe e tentarem persuadi-la com discursos acerca da completude e realização da mulher na maternidade ${ }^{(3)}$. O que evidencia que, mesmo com os espaços conquistados pela mulher moderna, sua associação ao papel materno ainda se faz presente.

O processo de transição da mulher-mãe para os demais papéis e espaços que tem ocupado vem sendo gradual e apresentado dificuldades, tais como o desgaste da mulher na conciliação de tantas funções. A dimensão de trabalhadora apenas se somou às outras já existentes ${ }^{(4)}$, de modo que a mulher continua sendo a principal responsável pelas tarefas domésticas e cuidados aos filhos, mas agora também está no mercado de trabalho e contribui financeiramente para o sustento da família.

Em contrapartida, em alguns contextos familiares, é possível notar que o homem tem compartilhado destas tarefas do lar, o que também indica um processo de transição, onde o pai se adequa a uma nova exigência da sociedade moderna e se implica cada vez mais nas tarefas que estão além do mercado de trabalho(5). Tal divisão começa a trazer algum equilíbrio entre os papéis de pai e mãe, no entanto, quando há esta divisão de responsabilidades, ainda é comum ouvir que o homem está "ajudando" a mulher no cuidado aos filhos e na organização da casa. Isso acaba por trazer a ideia de que a tarefa originalmente faz parte da responsabilidade da mulher, mas o homem está lhe prestando uma ajuda, situação esta que comumente confere ao homem o status de generoso, bom marido e bom pai. O que indica que, apesar de já ter havido alguma evolução nesta configuração familiar, ainda há uma longa jornada no que diz respeito a igualdade entre papéis de mãe e pai.

Frente ao exposto, é possível observar que a mulher é amplamente cobrada pela sociedade, em todos os meios em que se insere. Atender ao que hoje se espera da mulher, especialmente no papel materno, exige que esta tenha entrega, disponibilidade afetiva e amor incondicional ao seu filho. Entretanto, algumas condições podem prejudicar a execução desta função, como é o caso da dependência química, tema que junto à maternidade é nuclear nesta pesquisa.

A dependência química é definida como um transtorno mental caracterizado pelo "conjunto de fenômenos comportamentais, cognitivos e fisiológicos que se desenvolvem depois de repetido consumo de uma substância psicoativa"(6). Este transtorno atinge cerca de 27 milhões de pessoas no mundo. Estima-se que mais de 20 mil pessoas morrem a cada ano por problemas relacionados a drogas ${ }^{(7)}$.

Adependência química pode trazer consequências diversas à vida do usuário, da mesma maneira que das pessoas que constituem sua rede de relacionamentos, pois o uso de drogas, não raro, se torna prioridade na vida do dependente e, para dedicar-se ao uso, outros papéis e funções são descartados. Cabe notar que alguns desses papéis podem ser de fundamental importância, como as funções laborais que proveem o sustento do lar e funções paternas e maternas que prestam suporte ao crescimento dos filhos e são constituintes de suas personalidades.

Não se deve, no entanto, reduzir a dependência química aos seus sintomas e à sua dimensão psicopatológica. A atuação profissional deve compreender o sujeito de forma integral e sistêmica ${ }^{(8)}$; o que significa considerar as dimensões biológicas, psicológicas e sociológicas de cada pessoa, da mesma maneira que o contexto sócio, histórico e cultural em que cada um se insere.

Dados nacionais e mundiais fazem notar que o número de mulheres em dependência química ainda é substancialmente menor que o número de homens dependentes ${ }^{(6,9)}$. Todavia, o menor número de mulheres nesta condição não deve representar uma menor preocupação com o assunto, posto que o consumo de substâncias psicoativas entre estas tem sido crescente ao longo dos anos ${ }^{(6,9)}$. Assim, a diferença do uso de drogas por mulheres e homens 
tem, progressivamente, se estreitado.

No que se refere aos efeitos e consequências das drogas, existem evidências de que os danos atingem em maior proporção o público feminino. A estrutura fisiológica feminina favorece uma maior absorção de álcool pelo sangue, mesmo quando a mesma quantidade da substância é consumida por homens. Devido a isso, a dependência ao álcool, da mesma maneira que os problemas físicos decorrentes deste uso, incluindo risco de mortalidade, progridem mais rapidamente em mulheres ${ }^{(10)}$.

Em uma pesquisa realizada com mulheres dependentes químicas, foi identificado que elas apresentavam dificuldade em expressar os sentidos e significados de seus papéis sociais, de modo que não conseguiam falar sobre como se viam e sobre como percebiam serem vistas. Quando foram questionadas quanto a aspetos positivos e negativos em seus papéis de mãe, mulher, esposa e trabalhadora, "poucas conseguiram traduzir em palavras os papéis que representam, [...] falando de sua agressividade, falta de cuidados com os filhos, quando sob o efeito de substância química"(11), o que indica que o distanciamento de si e dos outros, da mesma maneira que a perda ou desconsideração de sua identidade são comuns na dependência.

Considerando os dados até aqui apresentados, é possível verificar que este estudo se aproxima de uma realidade cada vez mais presente na sociedade moderna, onde a mulher assume, protagoniza e concilia diversos papéis e funções, como mãe, esposa e dona de casa. Paralelo a isso, as tarefas do lar já não se fazem suficientes aos olhos da sociedade, de modo que a mulher passa também a ser cobrada por sua entrada no mercado de trabalho e construção de uma carreira. Com o progressivo aumento do uso de drogas entre as mulheres, cumprir com tudo que se espera de seus papéis pode se tornar uma tarefa ainda mais difícil. Assim, o objetivo desta pesquisa foi identificar a percepção de mães dependentes químicas sobre seu vínculo mãe-filho durante o período de uso de drogas e no período de recuperação.

\section{Método}

A presente pesquisa é qualitativa, exploratória e de corte transversal. Caracteriza-se como estudo de caso, posto que as histórias das participantes foram estudadas de forma ampla e em profundidade ${ }^{(12)}$.

As participantes desta pesquisa foram cinco mulheres frequentadoras de grupos de mútua ajuda da Grande Florianópolis. No período pesquisado, três frequentavam o grupo Narcóticos Anônimos (NA) e duas o grupo Alcoólicos Anônimos (AA). O critério para a seleção das participantes foi de acordo com a manifestação voluntária ao serem convidadas a participar da pesquisa e atenderem aos seguintes critérios de inclusão: ter idade superior a 18 anos e ter pelo menos um filho com idade entre 4 e 17 anos que acompanhou seu período de uso de drogas durante a primeira infância.

A delimitação desta faixa etária para os filhos se justifica por duas razões: com quatro anos a criança já passou por sua primeira infância; momento em que os níveis de consciência e verbalização tornam-se mais apurados. Com 17 anos o adolescente ainda está, legalmente, sob responsabilidade dos pais; o que exige destes uma maior implicação na criação e cuidados aos filhos. As mulheres participantes da pesquisa estão indicadas na Tabela 1. Com o intuito de preservar o sigilo destas mulheres, seus nomes reais foram alterados por nomes bíblicos, seguindo a máxima popular de que "mãe é sagrada".

Tabela 1 - Caracterização das participantes. Florianópolis, SC, Brasil, 2015

\begin{tabular}{|c|c|c|c|c|c|}
\hline Nome & Isabel & Miriã & Ana & Sara & Noemi \\
\hline Idade & 51 anos & 32 anos & 40 anos & 42 anos & 40 anos \\
\hline Escolaridade & $3^{\circ} \mathrm{grau}$ completo & $\begin{array}{c}1^{\circ} \mathrm{grau} \\
\text { incompleto }\end{array}$ & $\begin{array}{c}2^{\circ} \text { grau } \\
\text { completo }\end{array}$ & $\begin{array}{c}3^{\circ} \mathrm{grau} \\
\text { incompleto }\end{array}$ & Pós-graduação \\
\hline Idades dos filhos & $\begin{array}{l}29,22,18 \text { e } 05 \\
\text { anos. }\end{array}$ & $\begin{array}{c}12,10,9 \text { e } 7 \\
\text { anos. }\end{array}$ & 13 anos & 17 anos & 13 anos \\
\hline $\begin{array}{l}\text { Tempo que frequenta } \\
\text { o grupo de mútua } \\
\text { ajuda }\end{array}$ & $\begin{array}{l}\text { Alcoólicos } \\
\text { Anônimos - } 2 \\
\text { anos }\end{array}$ & $\begin{array}{l}\text { Narcóticos } \\
\text { Anônimos - } 4 \\
\text { meses }\end{array}$ & $\begin{array}{l}\text { Narcóticos } \\
\text { Anônimos - } \\
\text { 5anos }\end{array}$ & $\begin{array}{c}\text { Alcoólicos } \\
\text { Anônimos - } 3 \\
\text { meses }\end{array}$ & $\begin{array}{l}\text { Narcóticos Anônimos } \\
-1 \text { ano e } 5 \text { meses }\end{array}$ \\
\hline Drogas utilizadas & Álcool & $\begin{array}{c}\text { Álcool, cocaína } \\
\text { e LSD. }\end{array}$ & $\begin{array}{l}\text { Álcool e } \\
\text { cocaína }\end{array}$ & $\begin{array}{c}\text { Álcool, } \\
\text { maconha, } \\
\text { solvente, éter, } \\
\text { cola de sapato } \\
\text { e cocaína. }\end{array}$ & $\begin{array}{c}\text { Álcool, maconha e } \\
\text { cocaína }\end{array}$ \\
\hline $\begin{array}{l}\text { Tempo de uso de } \\
\text { drogas }\end{array}$ & 13 anos & 7 anos & 8 anos & 25 anos & 19 anos \\
\hline
\end{tabular}


Foi entrado em contato com os coordenadores dos grupos de mútua ajuda AA e NA, cujos telefones estão disponíveis nos sites oficiais destas irmandades, a fim de apresentar a pesquisa, seus objetivos e verificar o melhor dia para uma visita. Foi realizada visita a 10 grupos de mútua ajuda, com o intuito de encontrar mulheres dentro do perfil pretendido e convidá-las a participar do estudo. Três convites foram realizados pessoalmente e dois por telefone, através de indicação de outros membros dos grupos.

A coleta de dados foi realizada individualmente, a partir de entrevistas semiestruturadas que duraram, aproximadamente, 50 minutos. Três ocorreram nas salas dos grupos de mútua ajuda frequentados por cada participante e duas nas residências das participantes. O roteiro foi constituído por 22 questões que abordaram aspectos referentes ao vínculo entre mãe e filho, características da relação entre mãe e filho, incluindo consequências das drogas para esta relação e a caracterização do papel materno exercido pelas entrevistadas.

Cada questão presente no roteiro da entrevista foi feita de modo a buscar uma compreensão global de cada aspecto investigado. Para tanto, foi questionado como determinado aspecto da relação acontecia durante o período do uso de drogas e como este acontecia no período de recuperação, como cada entrevistada percebia essas mudanças e quais eram os sentimentos presentes em cada momento relatado. Para além de vivências concretas, as questões buscavam favorecer a expressão do significado e do sentimento das entrevistadas em cada etapa.

O presente estudo foi avaliado e aprovado pelo
Comitê de Ética e Pesquisa da Universidade do Sul de Santa Catarina, pelo CAAE: 19174713.1.0000.5369 e parecer 357.197. Antes do início da entrevista, cada participante assinou o Termo de Consentimento Livre e Esclarecido (TCLE) e o termo de autorização para gravação de áudio. Depois das entrevistas, os dados foram transcritos integralmente, organizados em categorias à posteriori e analisados utilizando a técnica de Análise de Conteúdo(13).

Através da leitura integral da transcrição das entrevistas, constatou-se uma significativa diferença entre comportamentos e sentimentos presentes no período de uso de drogas e durante a recuperação. Notou-se que os aspectos negativos da relação concentravam-se durante o período de uso de drogas e os positivos no período de recuperação. Durante o uso de drogas os comportamentos e sentimentos positivos eram ausentes ou, quando presentes, perdiam em termos de qualidade, pois vinham associados a sentimentos como pena, medo e vergonha. A partir daí, pensou-se em categorias que pusessem em evidência esse contraste, de modo a categorizar o que se tornou mais presente no discurso das entrevistadas, a saber: os afetos positivos, afetos negativos e o diálogo com os filhos.

\section{Resultados e discussão}

Para analisar o vínculo entre mãe e filho durante o período de uso de drogas e no período de recuperação, foram construídas três categorias à posteriori, conforme indicado na Tabela 2.

Tabela 2 - Categorias, período e frequência de respostas pertinentes ao eixo temático. Florianópolis, SC, Brasil, 2015.

\begin{tabular}{lccc}
\hline \multicolumn{1}{c}{ Categorias } & Período & Freq. & \multicolumn{2}{c}{ Participantes } \\
\hline Afeto positivo & Em uso de drogas & 04 & Isabel, Miriã, Ana e Sara \\
Afeto negativo & Em recuperação & 05 & Isabel; Miriã; Ana; Sara e Noemi \\
& Em uso de drogas & 04 & Isabel; Miriã; Sara e Noemi \\
Existência de diálogo & Em recuperação & 02 & Ana e Noemi \\
& Em uso de drogas & 00 & Sem ocorrência \\
& Em recuperação & 05 & Isabel; Miriã; Ana; Sara e Noemi
\end{tabular}

$\mathrm{Na}$ categoria Afeto positivo, que investigou a presença de sentimentos positivos da mãe com relação aos filhos, este afeto esteve presente na fala de quatro entrevistadas Em uso de drogas. Foi possível evidenciar que, apesar de haver uma consideração positiva em alguns momentos, este afeto se apresentou associado a sentimentos como medo de não poder atender efetivamente às necessidades emergenciais e cotidianas do filho, sentimento de vergonha, da mesma maneira que pena do filho por visualizá-lo em situação de vulnerabilidade: Eu tinha pena deles, porque mesmo usando drogas e estando na loucura, eu tinha alguns momentos de lucidez. Eu não lembrava se eles tinham comido, se eles tinham almoçado (MIRIÃ).

Já Em recuperação, o afeto positivo se apresentou associado ao carinho entre mãe e filho e apropriação da responsabilidade inerente ao papel materno, demonstrando a construção real de vínculos 
afetivos, como é possível observar na história de Isabel: Hoje eu beijo bastante, faço carinho. A gente está sempre falando coisas que antes eu não dizia, como 'eu te amo'. Dou bom dia, às vezes eu digo: 'tu é a coisa mais importante da minha vida'. Essas coisas eu não falava, eu não era uma mãe amorosa. Eu até tinha amor, mas eu não transmitia isso (ISABEL).

Nesse sentido, foi possível constatar que apesar da maioria das mães nutrirem sentimentos positivos pelos filhos em ambos os períodos, durante o uso de drogas esses sentimentos não se refletiam em suas ações. As mães se preocupavam com seus filhos, o que não as fazia deixar de usar drogas para resolver as situações que Ihes causavam preocupação; isso porque já haviam perdido o controle sobre sua dependência química. Já em recuperação, o afeto se demonstrou através de posturas ativas frente aos filhos, pois nesta condição elas se percebiam mais capazes de transmitir aos filhos sentimentos positivos.

As trocas de afetos positivos entre mãe e filho são determinantes para a estruturação de aspectos importantes do desenvolvimento da criança. É a partir de uma atmosfera de afeto e proteção em casa que a criança desenvolve a segurança necessária para relacionar-se com o meio social ${ }^{(14-15)}$. As consequências da qualidade destas interações, sejam elas positivas ou negativas, a acompanharão até sua vida adulta, estabelecendo tendências de como se colocará na relação com outras pessoas.

O afeto positivo em famílias que enfrentam a dependência química, no entanto, assim como encontrado na presente pesquisa, não é comum: "na maioria das vezes, os filhos [de dependentes químicos] sofrem com uma interação familiar negativa e um empobrecimento na solução de problemas"(16); essas famílias são tidas como disfuncionais e as consequências desta falta de aspectos positivos se refletem no desenvolvimento da criança.

Em pesquisa realizada com 54 filhos de alcoolistas, identificou-se que $94,4 \%$ deles apresentavam sentimento de inferioridade e inibição e $88,9 \%$ possuíam carência afetiva(16). Assim, tornase importante atentar para o padrão afetivo que estas crianças estão desenvolvendo, pois a tendência é que quando construírem suas próprias famílias, eles reproduzam essa falta de afeto, gerando um círculo vicioso $^{(14)}$

$\mathrm{Na}$ categoria Afeto negativo, que investigou a existência de sentimentos negativos com relação aos filhos, no período $E m$ uso de drogas quatro mães afirmaram ter percebido este tipo de afeto. Neste período, o afeto negativo esteve em maior parte relacionado a irritabilidade das mães por ter de prestar algum tipo de cuidado ou atenção ao filho, ao invés de poder dedicar este tempo ao uso de substâncias, como demonstra a fala de Isabel: As coisas que eu lembro é que às vezes me irritava eu ter que em vez de beber dar atenção para ele. (ISABEL).

$\mathrm{Na}$ história de Noemi, o afeto negativo se mostra desde a gestação, devido a necessidade desta mãe em ter de abdicar das drogas em prol da filha, ocasionando, em sua percepção, rejeição da gravidez: Eu estava curtindo, eu estava namorando a droga, eu tinha recém conhecido a cocaína. Eu tive uma gravidez muito complicada, eu tinha muita náusea, ameaça de aborto. Eu tive náusea até o final, cara. Rejeição total na gravidez (NOEMI).

Em recuperação, o afeto negativo foi percebido somente na história de duas mães. Enquanto Ana experienciou este afeto "por não saber lidar com situações" (sic), Noemi demonstra ter dificuldade em elaborar sentimentos positivos com relação à filha, havendo espaço apenas para o sentimento de culpa: Hoje eu continuo sentindo culpa. [...] Eu estou descobrindo alguns sentimentos ainda. Eu tenho só 1 ano e 5 meses de NA, eu ainda não descobri nenhum sentimento (NOEMI).

$O$ afeto negativo identificado na fala das entrevistadas foi um dos aspectos encontrados em uma pesquisa com seis mães colombianas dependentes químicas ${ }^{(17)}$. Durante o período de consumo de drogas as mães entendiam o papel materno como "difícil, árduo e desagradável" e a tarefa de cuidado aos filhos era assumida ou compartilhada com outros membros das famílias ${ }^{(17)}$, aspecto esse também identificado nesta pesquisa.

Os resultados quanto a existência de afeto negativo durante o período de uso de drogas são confirmados por autores que observam que as interações familiares negativas estão associadas ao consumo de drogas pelos pais da criança, o que faz com que o ambiente familiar esteja permeado por "baixa sensibilidade e afeto negativo, menos verbalizações e baixo nível de responsividade à criança"(18). Nesse sentido, foi possível verificar que o afeto negativo experienciado pelas entrevistadas é uma constante para a dependência química e esteve associado a prioridade que as drogas haviam conquistado na vida dessas mães. Assim, qualquer pessoa ou atividade que pusesse em risco essa prioridade e tomasse $o$ tempo que poderia estar investido no uso de drogas, era compreendida como entrave e causadora de irritabilidade, o que não aconteceu tão comumente na fase de recuperação.

Quanto às duas primeiras categorias, Afeto positivo e Afeto negativo, torna-se importante destacar a participação da entrevistada Noemi. Quanto aos sentimentos que esta mãe nutre pela filha, em um primeiro momento, quando questionada, 
a entrevistada afirmou possuir sentimentos positivos com relação à filha, o que foi desconstruído em um segundo momento. Foi possível perceber que a primeira resposta de Noemi estava, possivelmente, associada aos valores sociais, de forma que ela tentou trazer uma resposta socialmente melhor aceita:

Eu sempre amei muito ela. Ela sempre foi muito carinhosa, muito amada. Ela era muito querida. Nunca tive nenhum outro sentimento, eu sempre amei demais ela. (NOEMI - Primeira resposta quanto aos seus sentimentos pela filha). Eu acho que era só culpa que eu tinha por ela, não era nem amor. Eu só tinha culpa por ela. Hoje eu continuo sentindo culpa e eu vou te dizer uma coisa bem sincera, eu sentia ela como sendo uma pessoa muito estranha. Ela era uma estranha para mim (NOEMI - Segunda resposta quanto aos seus sentimentos pela filha).

A maternidade tende a ser vivenciada como o elemento determinante para o reconhecimento da mulher enquanto indivíduo, enquanto ser social ${ }^{(19)}$. Nesta direção, se destaca que "ser mãe hoje não é tão simples; recusar a sê-lo menos ainda"(19). Assim, é possível observar que socialmente se espera que a mulher exerça o papel materno e vivencie este momento como único e especial para sua vida.

A mulher que não demonstra o desejo pelo exercício desta função costuma ser alvo de estranhamento, questionamento e tentativas de persuasão(3), o que leva a constatar que a mulher na sociedade atual não tem espaço para expressar, ou mesmo construir, desejos próprios relacionados à maternidade que estejam contrários ao que se espera pelo social.

Quando se afirma que "os valores de uma sociedade são por vezes tão imperiosos que têm um peso incalculável sobre os nossos desejos"(20), se aponta para a dificuldade na construção de desejos que estejam incompatíveis com o social. Essa ambivalência de desejos esteve presente na história de Noemi que, apesar de referir ter planejado sua filha, quando soube da gravidez deu-se conta das consequências desta condição (condição esta que incluía cessar o "namoro" (sic) que esta mãe estava estabelecendo com a droga) e percebeu que, na verdade, nunca quis ser mãe.

Como consequência desses valores sociais, a mulher que não sente o que socialmente se espera frente à maternidade, tende a se sentir culpada e frustrada, pois percebe que falhou em seu papel enquanto mulher, ao não conseguir desejar a gravidez ou não amar incondicionalmente seu filho(19). A partir disso, cabe refletir sobre a "regra social" da maternidade: está socialmente posto que toda mulher deve ser mãe e que é a partir dessa função materna que ela se sentirá completa e realizada. Talvez seja mais fácil seguir a regra que está posta do que recusála e enfrentar conflitos e críticas sociais. Assim, é possível observar que esta mãe, em um primeiro momento, não se sentiu à vontade para expor um sentimento contrário ao que socialmente se espera do papel materno.

Na categoria Existência de diálogo, no período Em uso de drogas, nenhuma das entrevistadas acusou a existência do diálogo com seus filhos, o que faz ter em conta que a dependência química traz prejuízos importantes à interação familiar: Antes eu não conversava. Era o básico, botar roupa, comer, dormir. A hora que eu mais gostava é quando ele dormia (ISABEL).

O oposto ocorreu no período Em recuperação, onde todas as cinco entrevistadas percebem a existência de diálogo entre elas e seus filhos. A qualidade desta interação possui variação entre as entrevistadas, o que se entende como natural, posto que as experiências de cada família frente à dependência química, da mesma maneira que o tempo que cada membro necessita para conseguir reestabelecer vínculos, são singulares, como se percebe em algumas de suas falas: [Converso com a minha filha] muito, muito, muito. Os assuntos são variados. No momento a gente está conversando muito sobre a fase de ficar, porque ela está despertando para esse lado (ANA). Eu não consigo me aproximar muito dele ainda, eu acho que ainda estou muito no começo do processo de recuperação, mas eu vejo que ele me dá mais atenção quando eu falo, ele olha mais pra mim e há uma cumplicidade maior (SARA).

A partir da comunicação com a mãe, a criança significa a si mesma e o mundo à sua volta, sendo esta interação fundamental para a continuidade de seu desenvolvimento. É a partir da comunicação que a criança organiza seu pensamento, desenvolve percepções e se estrutura enquanto sujeito(21). Nesse sentido, ao considerar que a mãe tende a ser a maior referência para a criança, especialmente durante seus primeiros anos de vida, é importante que ela esteja disponível para apresentar o mundo à criança e acolher suas angústias e inquietações, através do caráter orientador e formador presente na comunicação.

Foi possível constatar que a fase de uso de drogas esteve repleta por afastamentos entre mães e filhos de diversas ordens, sendo o diálogo um dos aspectos mais prejudicados na vida dessas famílias. O prejuízo da qualidade do diálogo causado pela dependência química é um consenso entre a literatura, pois o dependente químico está com suas prioridades voltadas ao uso de drogas, o que gera um 
maior isolamento e, por consequência, a possibilidade de diálogo fica reduzida. Quando a comunicação acontece, tende a ser conflituosa, pois o ambiente familiar se encontra frágil e mobilizado(22).

\section{Considerações finais}

Esta pesquisa investigou o impacto do uso de drogas sobre o vínculo mãe-filho. Pôde-se constatar que a maternidade ocupa um lugar importante e especial para a maioria das mães; no entanto, durante o período de uso de drogas a prioridade foi direcionada ao consumo de substâncias e a maternidade foi deixada em segundo plano em diversos momentos. Durante o uso de drogas o amor sentido pelas mães não se refletia em suas ações, de modo que $\mathrm{o}$ afeto, o diálogo e as relações sociais foram, dentre outros, aspectos por vezes negligenciados; o que as distanciou do que socialmente se espera da maternidade.

O período de uso de drogas causou um afastamento global entre as mães e seus filhos em todos os aspectos investigados. Os vínculos estiveram significativamente fragilizados. Em recuperação, estas mães têm tentado reconstruir sua relação com seus filhos e diversos comportamentos relacionados a prestação de suporte, diálogo e transmissão de amor estão sendo reinseridos em suas relações familiares. No entanto, essa reconstrução de vínculo tem acontecido com mais dificuldade em alguns casos e algumas mães ainda não conseguem se aproximar de seus filhos; situação está que uma intervenção profissional poderia facilitar. Junto a isso, outro ponto que se mostrou passível de intervenção foi a resistência, especialmente de Noemi, em expressar os sentimentos reais que nutria pela filha; isso por estarem incompatíveis com o que socialmente se espera que as mães sintam.

Estes aspectos evidenciam a necessidade de que haja um espaço que preste atenção a essas mães e que vá além da dimensão da dependência química, considerando-as, antes de tudo, mulheres e mães. Nessas circunstâncias, a elaboração destes sentimentos será favorecida, o que pode possibilitar a atualização e reconstrução de sentimentos e vínculos.

Atualmente as mulheres dependentes químicas podem contar com dois principais serviços de suporte: CAPS-AD e grupos de mútua ajuda, como Alcoólicos Anônimos e Narcóticos Anônimos. Dentre estes, somente o CAPS conta com ajuda profissional, sendo que nos grupos de mútua ajuda o processo de recuperação ocorre por meio de depoimentos e a motivação dos colegas presentes. Nestes dois serviços há formação de grupos para atendimento aos dependentes químicos e seus familiares com foco na dependência química. Entretanto, em ambos, os grupos são compostos por homens e mulheres.

Evidencia-se aqui que a atuação com mulheres dependentes químicas exige uma intervenção multidisciplinar, que as considere - efetivamente - como sujeitos biopsicossociais. Ademais, essas mulheres necessitam de um espaço entre iguais, onde possam sentir-se à vontade para compartilhar as particularidades da dependência química feminina. Nas visitas realizadas aos grupos de mútua ajuda, as poucas mulheres presentes relataram a vergonha e dificuldade que tiveram antes de ingressar, por saberem que haveria homens partilhando de seus depoimentos.

\section{Referências}

1. Afornali $M$, Mestres R. Por trás da aparência singela de mãe. Curitiba: Popular; 2011

2. Klaus MH, Kennel JH, Klaus PH. Vínculo - Construindo as bases para um apego seguro e para a independência. Porto Alegre: ArtMed; 2000.

3. Patias ND, Buaes CS. "Tem que ser uma escolha da mulher!": representações de maternidade em mulheres não-mães por opção. Psicol Soc. 2012;24(2):300-6.

4. Borsa JC, Feil CF. O papel da mulher no contexto familiar: uma breve reflexão. Portal dos Psicólogos. 2008;185:1-12.

5. Wagner A, Predebon J, Mosmann C, Verza F. Compartilhar tarefas? Papéis e funções de pai e mãe na família contemporânea. Psicologia: Teoria e Pesqui. 2005;21(2):181-6.

6. Organização Mundial de Saúde. Classificação Estatística Internacional de Doenças e Problemas Relacionados à Saúde (CID-10). $5^{\mathrm{a}}$ ed. Porto Alegre: Artes Médicas; 1997.

7. Escritório das Nações Unidas sobre Drogas e Crimes. Relatório mundial sobre drogas 2012. Nova lorque; 2012. 8. Conselho Federal de Psicologia. Documento de referências técnicas para a atuação de psicólogas (os) em políticas públicas de álcool e outras drogas. Brasília: CFP; 2013.

9. Ministério da Justiça e Cidadania (BR). Secretaria Nacional de Políticas sobre Drogas. Relatório brasileiro sobre drogas. Brasília: SENAD; 2009.

10. Observatório Brasileiro de Informações Sobre Drogas (BR). Tratamento para populações específicas mulheres. Brasília: Ministério da Justiça do Brasil; 2012. 
11. Leal MBR. Ser mulher e dependente química: adesão ou adaptação do tratamento? [Monografia]. Brasília: Universidade de Brasília; 2009.

12. Gil AC. Métodos e técnicas de pesquisa social. $5^{\mathrm{a}}$ ed. São Paulo: Atlas; 1999.

13. Bardin L. Análise de conteúdo. $5^{\mathrm{a}}$ ed. Lisboa: Edições 70; 2010.

14. Bowlby J. Apego e perda. São Paulo: Martins Fontes; 1993. v. 3.

15. Mendes DM LF, Pessôa LF. Comunicação afetiva nos cuidados parentais. Psicol Estud. 2013;18(1):15-25.

16. Figlie N, Fontes A, Moraes E, Payá R. Filhos de dependentes químicos com fatores de risco biopsicossociais: necessitam de um olhar especial? Rev Psiquiatr Clín. 2004;31(2):53-62.

17. Roldan MCB, Galera SAF, O'brien B. Perception of the mothering role of women who live in drug and violence context. Rev. Latino-Am. Enfermagem. [Internet]. 2005 [Access Ago 10 2016];13(spec. number). Available from: http://www.scielo.br/pdf/rlae/v13nspe2/pt_v13nspe2a04. pdf

18. Zanoti-Jeronymo DV, Carvalho AMP. Alcoolismo parental e suas repercussões sobre crianças e adolescentes: uma revisão bibliográfica. SMAD, Rev. Eletrônica Saúde Mental Álcool Drog. (Ed. port.) [Internet]. 2005, vol.1, n. 2 [Acesso 11 ago 2016]. pp. 0-0 . Disponível em: <http://pepsic.bvsalud.org/scielo.php?script=sci_ arttext\&pid=S1806-69762005000200007\&lng=pt\&nrm=i so>

19. Tourinho JG. A mãe perfeita: idealização e realidade - Algumas reflexões sobre a maternidade. IGT na Rede. 2006;3(5):1-33.

20. Badinter E. Um amor conquistado: o mito do amor materno. Rio de Janeiro: Nova Fronteira; 1985.

21. Molina RS, Fabriani CB. Relação mãe-filho: fator de Construção do Cidadão. Pensamento Plural. 2011;5(1):49-57.

22. Rocha AP. As problemáticas enfrentadas pelas famílias co-dependentes no tratamento da dependência química no âmbito do programa amor-exigente no município de Ponta Grossa - Pr [Monografia]. Ponta Grossa: Universidade Estadual de Ponta Grossa; 2011. 